\title{
CONTINUING MEDICAL EDUCATION: CLOSING THE GAP BETWEEN MEDICAL RESEARCH AND PRACTICE
}

\section{*E. Ogbaini-Emovon}

*Department of Medical Microbiology, University of Benin Teaching Hospital, Benin City, Nigeria

\section{Correspondence:}

E. Ogbaini-Emovon

Department of Medical Microbiology

University of Benin Teaching Hospital

P.M.B. 1111 Ugbowo

Benin City, Nigeria

Email: ephogbaini@yahoo.com

\section{ABSTRACT}

Continuing medical education (CME) has long been recognized as the key to updating and maintaining the knowledge and skill of health professionals.CME activities are well advocated, accepted and regulated in the developed world with sanctions for non-participation. In developing countries, including West Africa subregion, CME activities are less effective and no practical enforcement to compel individual's participation.

This review examined the importance, scope and regulation of CME activities and identified the barriers to effective CME in developing countries to include lack of motivation, time, finance and lack of access to CME facilities occasioned by underdevelopment in information and communication technology (ICT) and know-how. It is concluded with practical suggestions that; health professionals should embrace CME as a moral and ethical obligation; health organizations and institutions should provide incentives, adequate funding and protected time for CME activities; professional and regulatory bodies should enforce participation and impose sanctions if need be, as the way forward.

\section{INTRODUCTION}

Medical education and learning never ends, especially amongst professionals. It does not stop after graduation from the medical school, as all the knowledge and skill required by the doctor cannot be taught in the medical school. Medical knowledge is dynamic, it changes with the evolution of new technologies and advances in biomedical science. Pre-service (undergraduate) training does not adequately equip students with adequate skills on how to cope with these changes as well as the changing environment concerning communication skills, ethical and human rights issues, management skills, basic research skills, information technology and so forth1. Continuing medical education (CME) entails inservice training necessary to update knowledge and skills and maintain an effective and relevant delivery of health task under changing conditions2. According to the American Medical Association (AMA) and the Accreditation Council for Continuing Medical Education (ACCME), Continuing Medical Education (CME) is defined as educational activities which serve to maintain, develop, and increase the knowledge, skills and professional 
performance that physicians and allied health professionals use to provide services for patients, the public or the profession. The title CME per se appears to imply that its thrust is medical or clinical work, whereas, CME extend beyond actual clinical work and include research, audit, managerial activities, attendance at local and international conferences, writing articles for publications etc, hence in the UK the term continuing professional development (CPD) is favoured3. For practical purposes CME and CPD can be used interchangeably. CPD is an umbrella term applicable to other professions by which members of professional associations maintain, improve and broaden their knowledge and skills and develop the personal qualities required in their professional lives or the conscious updating of professional knowledge and the improvement of professional competence throughout a person working life3.

This write-up attempts to re- echo the concept of CME as a key to improving medical practice with emphasis on the contending issues in the developed and developing countries and the various means of $\mathrm{CME}$, its regulation, funding and the barriers to effective CME in West Africa. Finally it is concluded with some practical suggestions on the way forward for the sub-region.

\section{Contending issues: CME in developed versus developing countries In Europe} and America, a national board is usually responsible for the quality of CME in their countries and decide on reward or sanction for participation and non-participation. CME providers apply for CME accreditation from an advisory professional committee (APC) and will be given the number of CME credit corresponding to their manifestations.
Essentially every CME activity attracts some credits to the participant. For example, the Royal College of Pathologist CME program5, one CME credit equates to one hour of learning time. Members must collect 250 credits over five years. College guidelines outline the categories of educational events and activities that can earn credits. All participants must keep a log book that is ratified by the local college tutor and sent to the college annually. Participants are awarded certificate of attendance, stating the number of CME credit obtained. Any sanction for nonparticipation has to be taken by the national body dealing with certification of specialist and professionals. In case of medical litigation, individual specialist may be required to proof that he or she has attended CME events. CME may be provided by; professional associations, post graduate colleges, medical schools, pharmaceutical companies as part of marketing strategy, hospital departments especially teaching and some private specialist hospitals (residency training, clinical meetings, grand ward rounds, seminars, etc), international organizations such as WHO and UNICEF-usually for specific groups6. Funding is often provided by individual participants, employer, pharmaceutical companies, NGOs, professional associations, government ministries/agencies, or international agencies6. In West Africa and most developing countries, CME activities are not intensive, and participation is at a very low ebb. There is virtually no enforcement by external verification or professional /governmental demand for recertification, revalidation, or accreditation of qualification and competence6. A few governmental institutions such as ministries of health and registration bodies have threatened mandatory recertification 
for doctors, this is yet to be enforced. Therefore, there is no incentive or sanction for participation in CME. Funding of CME is mainly by individuals, and sometimes by employer and occasionally by pharmaceutical companies as part of their marketing strategies. Doctors working in teaching hospitals fortuitously participate in on-going training activities meant for residents or medical students. These activities include grand ward rounds, seminars, journals clubs and chart reviews. These are open to other doctors not working in the hospital and those interested do attend. Apart from government- own hospitals, a few private 'specialist' hospitals-some accredited for training of residents in general medical practice-also organize similar internal CME activities. Also professional associations organize conferences, which are usually annual and during which lecture-type CME activities and seminars take place. Postgraduate colleges and some medical schools also organize topic specific seminars, updates courses, and workshops-most of which are targeted at residents preparing for examinations of the colleges but are also open to other doctors. There are no known surveys, but it is unlikely that more than $10 \%$ of doctors practicing outside teaching health institutions take part in CME activities in the subregion6. International organizations such as WHO and UNICEF occasionally sponsor topic or skillspecific workshops, which are open to specific group of doctors and health professionals.

\section{Commentaries on CME}

\section{CME Events3,4}

These include live events such as;

1) Attending meetings, conferences, seminars and symposia to the discipline of interest or related to it. e.g clinicopathology conferences.

2) Preparing and giving lectures and presentations in national and international meetings.

3) Visiting a recognized centre in the own country or abroad for one week or more, to update ones knowledge or acquire a new technique.

4) Writing papers in the field or related field, publishing books, as well as editing.

5) Embarking on a diploma or certificate course in a specialist or non-specialist area.

6) ICT-based packages; these include audio such as telephones, radios etc, video e.g television, videoconferencing and telemedicine. Other distancelearning packages such as electronic mail, internet, compact discs, etc are available The content of CME activities is determined by the regulating and professional bodies or colleges and all activities must be approved by such bodies in advance.

\section{Individual's Motivations and Benefits for Participating in CME Activities}

It has repeatedly been shown that CME is motivated by several factors among different health professionals and these amongst others include; improve care of patients, intellectual challenge to provide evidence of competence, compliance with employer's and professional bodies requirements, awareness of shortcomings, fear of litigation, and need for updating, as well as anticipated need7,8. In this information age, it is the survival of the fittest and CME is a key to optimizing a person's career opportunities for today and for tomorrow. 
The benefits accruing from CME cannot be overemphasized and include personal development and fulfillment in keeping up to date, professional growth, capacity for new responsibilities, re-certification by professional bodies, improve patient care, reduce cost of treatment, medicolegal protection, and ability to manage change 9,10 .

\section{Barriers to CME in Developing countries}

In developing countries, Nigeria inclusive, several factors have been identified as militating against CME. These can be summarized as follows:

- Motivation - There is no motivation except for self aggrandizement to participate in CME, or admission into membership of some specialist medical association. The need for CME certificate is not sufficiently appreciated in developing countries. There is no incentive or sanction for non- participation.

- Time - Doctors need time for study, reflection and to attend learning courses. Lack of time due to pressure of work and lack of funded study leave have identified as major barrier to CME activities11,12,13. Except for teaching hospitals, there is no protected time for CME during the workday. Management considers allotting time for CME as a luxury.

- Finance - Most doctors have to pay for their participation in external CME activities. In developing countries, salaries are just enough to meet basic family needs and many doctors have to work extra hours in private practice to supplement salaries, there is little to spare. In most health organizations there are no budget lines for CME6.
- Access - Information about CME are not widely distributed, so many doctors, especially those working in rural areas are not aware of even professional conferences until after the event. In this electronic age, many CME activities are available on CDROM or can be accessed via the internet, but you need to own a computer and have a telephone line. These are not readily available to most doctors practicing in the region.

- Know-how - Effective CME requires self-directed learning and a reflective medical practice. Traditional medical education least prepares doctors for this and the skills of acquiring, appraising and analyzing information for decision making are not taught. Many doctors lack basic ICT knowledge required for accessing information on-line.

- Acceptability-The characteristic of CME activities that are likely to be acceptable and effective have been described by various authors1,14,15. Most CME activities outside the teaching hospitals in the sub-region are based on attending professional meetings and national conferences. These activities are often not tailored towards individual needs. It has been widely appreciated that professionals preferred a wide variety of activities that are vocational, flexible, relevant and link theory with day to day practice, as against college scheme that tended to favor academic activities over more practical and local based ones 16,17

\section{CONCLUSION}

AND

\section{RECOMMENDATION}

CME is a sine qua non in order to bridge the gap between medical 
research and practice, especially in developing countries, where CME is under implemented. In the developed world where evidence of participation in CME activities is a pre-requisite for re-certification or renewal of practicing license, as well as for medico-legal protection, CME has become mandatory and the system is better for it. On the contrary, the non enforcement of CME and the lack of sanctions by the professional and regulatory medical bodies account for the levity and lackadaisical attitude of medical professionals in developing countries. Also, poor remuneration of medical practitioners coupled with technological underdevelopment are major obstacles to effective CME in in developing countries as majority of health professionals cannot afford and access CME activities, especially with modern ICT technolology

In order to scale- up CME activities in the developing countries, all hands must be on deck at the level of the health professional, health organizations, government, NGOs and international organizations. The following are recommended as way forward:

- Doctors and other health professionals should accept CME as a moral and ethical obligation to continue lifelong learning in order to maintain and improve their competence and performance without waiting for government legislation or sanction to force the profession and professionals into mandatory CME.

- Health organizations must restructure their institutional practice so that protected time is provided during the work day for CME activities.

- CME should be given priority and funding provided for organizational learning, acquisition of resource materials and sponsorship for individual learning. In all health organizations, a well respected senior colleague should be appointed and given full authority to function and co-ordinate CME activities in every health institution. It is increasingly being recommended that CME be accepted as part of employment requirement, and possibly the cost negotiated with the employer18

- Organizational CME should involve all health professionals involved in patient care in the institution, and should be varied and structured around the practice in the institution. Activities should include interactive practice-based activities such as case presentation, seminars, invited lectures, skill specific workshops etc. Being inter professional, these would foster better team work for the benefit of the patient.

- Self directed learning should be encouraged and organization should support participation in external CME by giving some incentives for this such as during promotion exercise or selection for other benefits and recognition

- Networking and collaboration: Links should be developed with nearby teaching institutions or bigger centers ,who should provide CME educators for specific topics or skills

- CME should be monitored and evaluated. There should be establishment of a council for each country with representation drawn from the ministry of health, medical associations, medical schools, middle level training colleges for health care professionals, the medical and dental council, nursing and midwife council, and the 
equivalent bodies of laboratory technicians. This council will design a CME curriculum suitable for various health professionals. It will also audit tools for evaluating personal and professional development and CME accreditation. Countries at the regional level may adopt to have similar structures and representation and agree upon reciprocal recognition of each others CME accreditation

- CME should be flexible and made to respond to individual need of participants. This can be achieved by quality control of CME. For example, every member attending CME event should make a statement about the content and usefulness of the event by filling questionnaire. Based on these, a CME event may be removed or added from the annual list of the following year

- Since CME is increasingly being accessed via ICT, there is need to introduce and maintain ICT at all levels of health care delivery within the context that is feasible, acceptable and affordable to those who use it..This may be as simple as a radio and television, already integrated into the daily lifestyle and daily activities of ordinary people or as complex as the computer based internet network which is more sophisticated and demanding in setting up and operation. Establishment of appropriate ICT and training of health professionals in information and communication technology has been demonstrated to impact positively on CME19,20,21 and this development is fast advancing the frontiers of CME in developing countries.

- Finally, all relevant professional and regulating bodies of medical practice should rise up to the challenge of enforcing CME to the letter and muster the political will to impose sanction if need be.

\section{REFERENCES}

1. Demissie H; Gille D, Eugene $E$, et al. Education of health professionals and the human resources crises in Africa. Mera 2003; 4:4-5

2. Davies D. Continuing medical education: global health, global learning. Brit Med J 1998; 316:385-9.

3. Eluzai $A \mathrm{H}$, Continuing medical education in Africa-an East African perspective. Mera 2003; 4:10-11.

4. Flynn F V,The Royal college of pathologists CME scheme. Postgrad Med J 1996, 72(suppl 1):24-5

5. Clair du Boulay, Conttinuing medical education for pathologist: an evaluation of the royal college of pathologists Wessex pilot scheme. J Clin Pathol 1997; 50:1022-1026.

6. Kayode A O, Kabba $T$ J. Scaling-up continuing medical education in West Africa. Mera 2003; 4:7-9.

7. SCOPME Continuing professional development for doctors and dentists. Working Paper 1994.

8. Sylvester $\mathrm{S} H \quad \mathrm{H}$. General practitioners' attitudes to professional reaccreditation. BMJ 1993; 307:912-14. 
9. Troxel D B, Sabella J D, Problem areas in pathology practice: uncovered by a review of malpractice claim. Am J Surg Path 1994; 18:821-31.

10. Nicol F. Making reaccreditation meaningful. $\mathrm{Br} J$ Gen Pract. 1995; 45:321-4.

11.Paeston M J T.Consultants perfections of CME and teaching time. Hospital update 1994; Aug:414-17

12. Continuing medical education (editorial) Lancet 1993; 342:1497-8.

13. Kerr DNS, Jones SAM, Easmon CSF. Continuing medical education: experience and opinion of consultants. BMJ 1993; 306:1398-402.

14. Clayton B. Continuing medical professional development for doctors and dentists. Postgrad Med J. 1996, 72 (suppl 1) 30:2

15.Davis $D A$, Thompson $M A$, Oxman $A$, et al. Changing physician performance: a systematic review of the effect of continuing medical education strategies. JAMA 1995; 274:700-5.

16. Mayne K, Practice-linked continuing medical education. Med J Aus 1994;161:630-2

17. Davis D A. The science and practice of continuing medical education: a study in dissonance. Ann Intern Med 1993; 118: A18-19.

18. Hangartner R. Continuing medical education in Europe. Postgrad Med J 1996; 72 (suppl 1):4-5.

19. Barnes B E. Creating the practice-learning environment: using information technology to support a new model of continuing medical education. Acad. Med. 1998; 73:278-281.

20. Manning $P$ R. Continuing medical education: the next step. JAMA 1983; 249:10421045.

21. Piemme T E. Computerassisted learning and evaluation in medicine. JAMA 1999; 260:367-372. 